\title{
Background reduction at DTU Nutech surface gamma laboratory
}

\author{
Markovi, Nikola; Roos, Per; Nielsen, Sven Poul; Cai, Xiao Xiao
}

Published in:

Applied Radiation and Isotopes

Link to article, DOI:

10.1016/j.apradiso.2019.05.014

Publication date:

2019

Link back to DTU Orbit

Citation (APA):

Markovi, N., Roos, P., Nielsen, S. P., \& Cai, X. X. (2019). Background reduction at DTU Nutech surface gamma laboratory. Applied Radiation and Isotopes, 151, 30-38. https://doi.org/10.1016/j.apradiso.2019.05.014

\section{General rights}

Copyright and moral rights for the publications made accessible in the public portal are retained by the authors and/or other copyright owners and it is a condition of accessing publications that users recognise and abide by the legal requirements associated with these rights.

- Users may download and print one copy of any publication from the public portal for the purpose of private study or research.

- You may not further distribute the material or use it for any profit-making activity or commercial gain

- You may freely distribute the URL identifying the publication in the public portal

If you believe that this document breaches copyright please contact us providing details, and we will remove access to the work immediately and investigate your claim. 


\section{Background reduction at DTU Nutech surface gamma laboratory Supplementary Information}

\section{https://doi.org/10.1016/..apradiso.2019.05.014}

\section{Appendix 1}

A test with nitrogen gas from a pressurised cylinder that had been left for a few months to age has been undertaken. Flow rate was controlled and measured with a welding gas flow meter. No effect on background was observed, Table A1.1. There is even a slight increase in the low energy count rate for $4 \mathrm{l} / \mathrm{min}$ flow. It could be due to the increased noise and vibration induced by such a high flow-rate. This supports the results from Section 3.1 that purging with LN2 boil off is enough for radon background reduction; at least in our case where the cosmic component is dominating.

Table A1.1 Change of count rate with gas flow. Total count rate is ROIs is shown, as measurement times with gas on were too short to obtain peak areas with good statistics.

\begin{tabular}{|c|r|l|l|l|r|r|r|}
\hline \multirow{2}{*}{\begin{tabular}{c} 
Flow $\begin{array}{c}\text { rate } \\
(\mathrm{I} / \mathrm{min})\end{array}$ \\
\cline { 3 - 8 }
\end{tabular}} & $\begin{array}{c}\text { measurement } \\
\text { time }(\mathrm{s})\end{array}$ & $40-60$ & $40-220$ & $40-2100$ & $293.4-296.9$ & $349.6-353.4$ & $607.4-611.6$ \\
\hline 0.6 & 57157 & $4.4 \mathrm{E}-02$ & $3.8 \mathrm{E}-01$ & $1.3 \mathrm{E}+00$ & $6.2 \mathrm{E}-03$ & $5.5 \mathrm{E}-03$ & $3.4 \mathrm{E}-03$ \\
\hline 1 & 42281 & $4.4 \mathrm{E}-02$ & $3.7 \mathrm{E}-01$ & $1.3 \mathrm{E}+00$ & $6.0 \mathrm{E}-03$ & $5.1 \mathrm{E}-03$ & $4.0 \mathrm{E}-03$ \\
\hline 4 & 41756 & $4.6 \mathrm{E}-02$ & $3.8 \mathrm{E}-01$ & $1.3 \mathrm{E}+00$ & $5.5 \mathrm{E}-03$ & $5.9 \mathrm{E}-03$ & $4.0 \mathrm{E}-03$ \\
\hline LN2 & 413658 & $4.4 \mathrm{E}-02$ & $3.7 \mathrm{E}-01$ & $1.3 \mathrm{E}+00$ & $6.4 \mathrm{E}-03$ & $6.3 \mathrm{E}-03$ & $4.5 \mathrm{E}-03$ \\
\hline$/$ & 86779 & $4.5 \mathrm{E}-02$ & $3.8 \mathrm{E}-01$ & $1.3 \mathrm{E}+00$ & $7.5 \mathrm{E}-03$ & $8.4 \mathrm{E}-03$ & $5.5 \mathrm{E}-03$ \\
\hline
\end{tabular}




\section{Appendix 2}

Medical cyclotron laboratory is situated some 100 meters away from the gamma laboratory. On very rare occasions, a sharp increase in neutron flux can be observed in the gamma spectra. That is especially evident in the spectra of detectors with Cd lining. The latest event was observed on 10 November 2017 (acquisition started 8/11/2017). Unfortunately, we have a 142000 seconds spectrum, but the excess neutron flux probably lasted only for a few hours in the morning of 10 November; that information we got from communication with cyclotron operators. Figs A2.1 and A2.2 show a sharp increase in $558 \mathrm{keV}$ line count rate and total integral count rates. Table A2.1 gives relative increase in count rate of selected lines. Also average count rates are presented and count rates in neutron induced peaks based on assumption that event lasted for 3 hours (with average count rate subtracted).

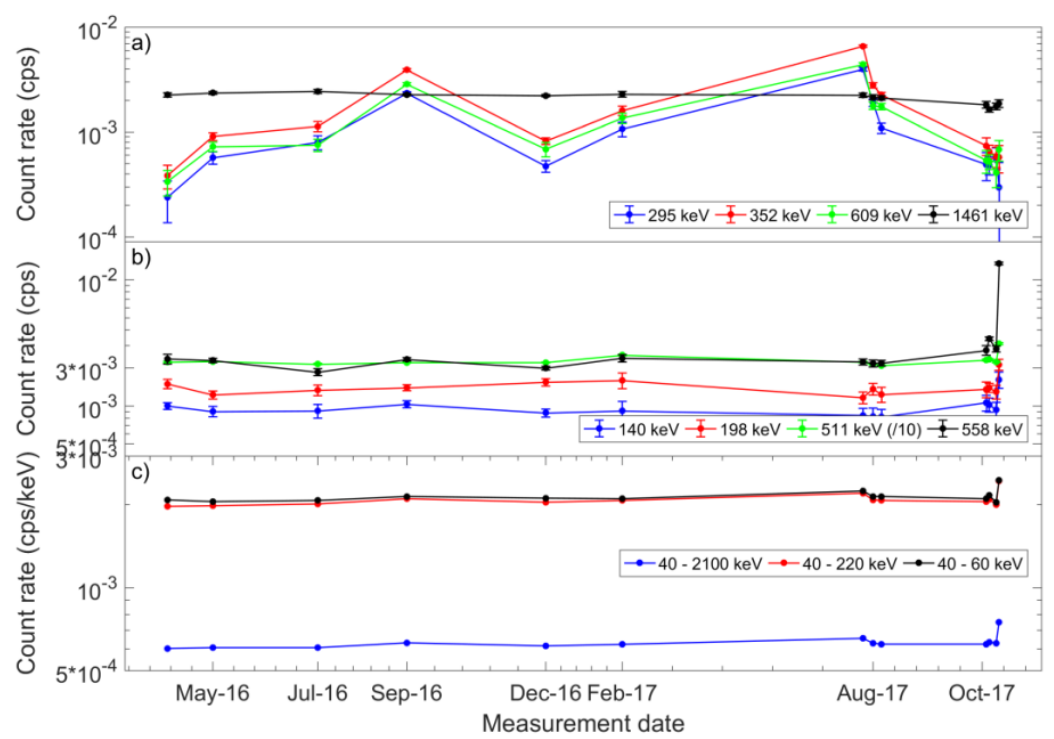

Fig. A2.1 Results from Fig. 2 extended for the new measurement with increased neutron flux.

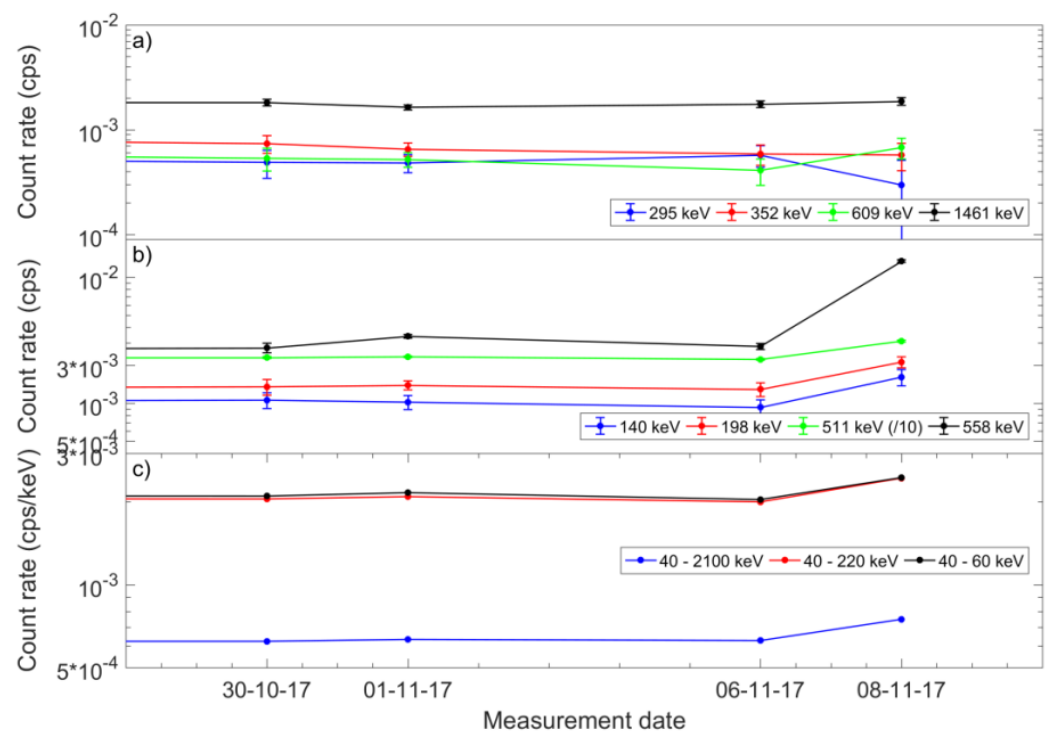

Fig. A2.2 Zoom-in on the last ten days background measurement results. 
Table A2.1 Relative increase in selected count rates indicates an excess in neutron flux. Last column is calculated in a way that average count rate is subtracted and the rest of counts is divided by an estimate irradiation time of 3 hours. Last three rows have count rates in $\mathrm{s}^{-1} / \mathrm{keV}$.

\begin{tabular}{|c|c|c|c|c|c|c|}
\hline \multirow[b]{2}{*}{ Source } & \multirow[b]{2}{*}{$\begin{array}{l}\text { Energy } \\
(\mathrm{keV})\end{array}$} & \multicolumn{2}{|c|}{ Count rate $\left(\mathrm{s}^{-1}\right)$} & \multirow{2}{*}{$\begin{array}{c}\text { Relative } \\
\text { increase } \\
(\%)\end{array}$} & \multirow{2}{*}{$\begin{array}{l}\text { Excess } \\
\text { counts }\end{array}$} & \multirow{2}{*}{$\begin{array}{l}\text { Count rate for } \\
3 \text { hours }\left(\mathrm{s}^{-1}\right)\end{array}$} \\
\hline & & average & 10-Nov & & & \\
\hline $75 \mathrm{mGe}$ & 139 & $9.6 \mathrm{E}-04$ & $1.6 \mathrm{E}-03$ & 68 & 92 & $8.5 \mathrm{E}-03$ \\
\hline $71 \mathrm{mGe}$ & 198 & $1.4 \mathrm{E}-03$ & $2.1 \mathrm{E}-03$ & 49 & 99 & $9.1 \mathrm{E}-03$ \\
\hline 214-Pb & 295 & 8.4E-04 & 3.0E-04 & -65 & -77 & $-7.1 \mathrm{E}-03$ \\
\hline $214-\mathrm{Pb}$ & 351 & $1.4 \mathrm{E}-03$ & 5.7E-04 & -60 & -123 & $-1.1 \mathrm{E}-02$ \\
\hline Annihilation & 511 & $2.2 \mathrm{E}-02$ & 3.1E-02 & 39 & 1234 & $1.1 \mathrm{E}-01$ \\
\hline $114 * \mathrm{Cd}$ & 558 & 2.9E-03 & 1.3E-02 & 357 & 1484 & 1.4E-01 \\
\hline $74 * \mathrm{Ge}$ & 596 & $8.5 \mathrm{E}-03$ & 1.1E-02 & 28 & 333 & $3.1 \mathrm{E}-02$ \\
\hline 214-Bi & 609 & $1.0 \mathrm{E}-03$ & $6.8 \mathrm{E}-04$ & -33 & -48 & $-4.4 \mathrm{E}-03$ \\
\hline $114 * \mathrm{Cd}$ & 651 & $3.2 \mathrm{E}-04$ & 2.1E-03 & 537 & 245 & 2.3E-02 \\
\hline $72 * \mathrm{Ge}$ & 691 & $4.8 \mathrm{E}-03$ & $6.6 \mathrm{E}-03$ & 37 & 254 & $2.4 \mathrm{E}-02$ \\
\hline $40-K$ & 1460 & $1.8 \mathrm{E}-03$ & 1.9E-03 & 4 & 10 & $-3.5 \mathrm{E}-03$ \\
\hline Integral & $40-2100$ & $1.3 \mathrm{E}+00$ & $1.5 \mathrm{E}+00$ & 20 & 36883 & $3.4 \mathrm{E}+00$ \\
\hline Counts/keV & $40-2100$ & $6.2 \mathrm{E}-04$ & 7.5E-04 & 20 & 18 & $1.7 \mathrm{E}-03$ \\
\hline Counts/keV & $40-220$ & $2.0 \mathrm{E}-03$ & $2.4 \mathrm{E}-03$ & 21 & 60 & $5.5 \mathrm{E}-03$ \\
\hline Counts/keV & $40-60$ & $2.1 \mathrm{E}-03$ & 2.4E-03 & 18 & 52 & $4.9 \mathrm{E}-03$ \\
\hline
\end{tabular}

Count rates of thermal neutron activation lines of Ge crystal (139 keV and $198 \mathrm{keV}$ sharp peaks) and fast neutron inelastic scattering on Ge crystal (596 keV and $691 \mathrm{keV}$ broad peaks, Fig.A.2.3 and Fig.A.1.4) show similar increase compared to average background count rate. Lines originating from Cd activation are much more pronounced.

If equations from the Section 3.3 are used for neutron flux estimation, for $3 \mathrm{~h}$ irradiation time, we obtain:

- $\Phi_{\mathrm{T}}=(2.3 \pm 0.5) * 10^{2} \mathrm{~s}^{-1} \mathrm{~m}^{-2}$ for the thermal neutron group that is around tenfold increase compared to background.

- $\quad \Phi_{\mathrm{F}}=(1.4 \pm 0.7) * 10^{3} \mathrm{~s}^{-1} \mathrm{~m}^{-2}$ for fast neutron group that is around 5 times increase compared to normal background neutron flux.

Problem of much higher Cd increase is not resolved and needs calculation of FEP efficiency for detection of Cd induced lines generated in Cd lining, along with cross sections for interaction of neutron of selected energies (we don't know the neutron energy spectrum now) with Cd. Actually, if further developed, that can be used similar to formulas form Section 3.3 for neutron flux calculation based on Ge lines; for count rate in selected Cd peak we get:

$$
I=N_{C d} \varepsilon_{F E P} \int \sigma(E) \Phi(E) d E
$$

Where $\mathrm{N}_{C d}$ is the number of Cd atoms in the lining, $\varepsilon_{F E P}$ is FEP efficiency for detection of selected line, $\sigma(E)$ is the cross-section for the selected Cd line and $\Phi(E)$ is neutron flux.

Did we hit a resonance for ${ }^{113} \mathrm{Cd}(\mathrm{n}, \gamma){ }^{114} \mathrm{Cd}$ reaction? 


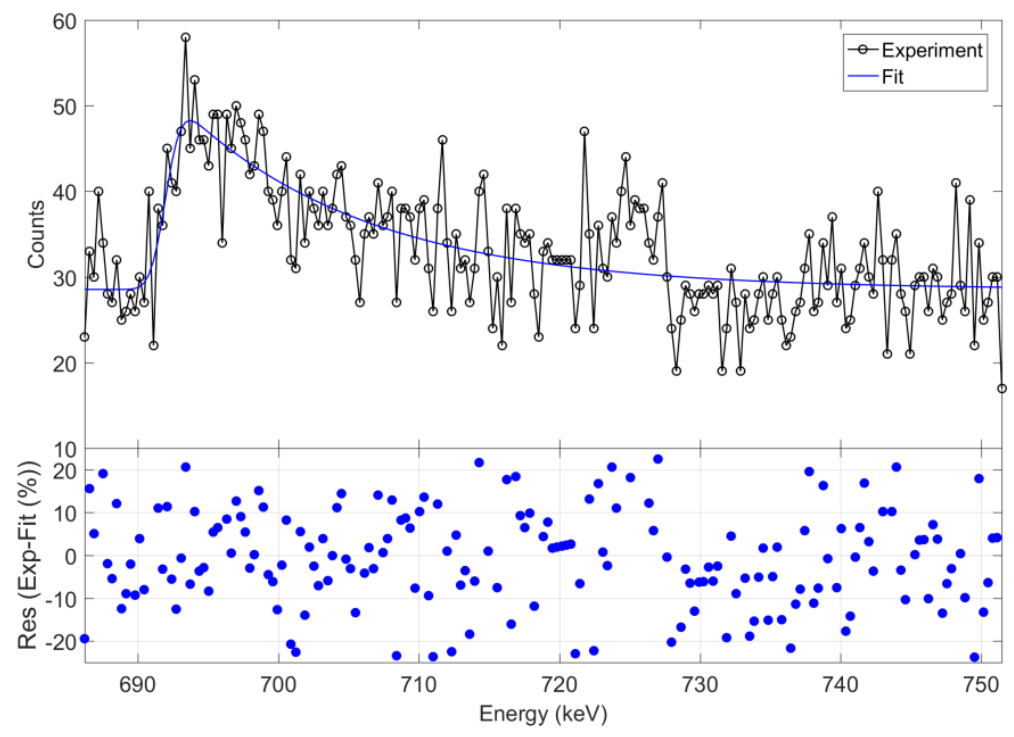

Fig. A2.3 Fast neutron activation line in HPGe detector. The spectrum is 1.5 day background spectrum on DET008. The fit to ${ }^{72} \mathrm{Ge}\left(\mathrm{n}, \mathrm{n}^{\prime}\right)^{72} \mathrm{Ge}$ broad peak and background continuum is shown in blue. Details of fitting procedure given in Appendix 5.

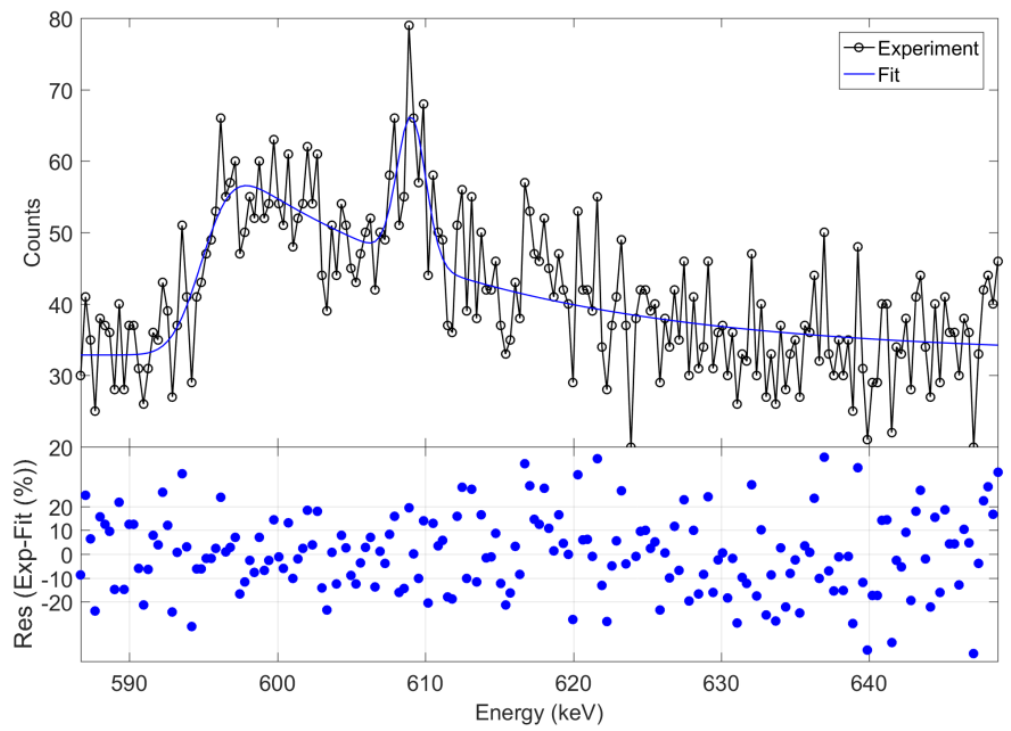

Fig. A2.4 The fit to ${ }^{74} \mathrm{Ge}\left(\mathrm{n}, \mathrm{n}^{\prime}\right){ }^{74} \mathrm{Ge}$ broad peak, $609 \mathrm{keV}{ }^{214} \mathrm{Bi}$ background line and background continuum is shown in blue. Details of fitting procedure given in Appendix 5. 


\section{Appendix 3}

BEGe5030 detector EGSnrc model development is described. The same detector we used is described in (Mekarski, Zhang, Liu, \& Ungar, 2017); (Bruggeman, Vidmar, Amouriq, \& Verheyen, 2014) use 0.3 um for their top dead layer and 50 um for side; Andreotti and Hult also claim 0.3 um top dead layer (Andreotti et al., 2014) and 800 um side. Details are not important now as neutron flux calculations are only approximate.

We use 0.5 um top and 800 um side dead layer.
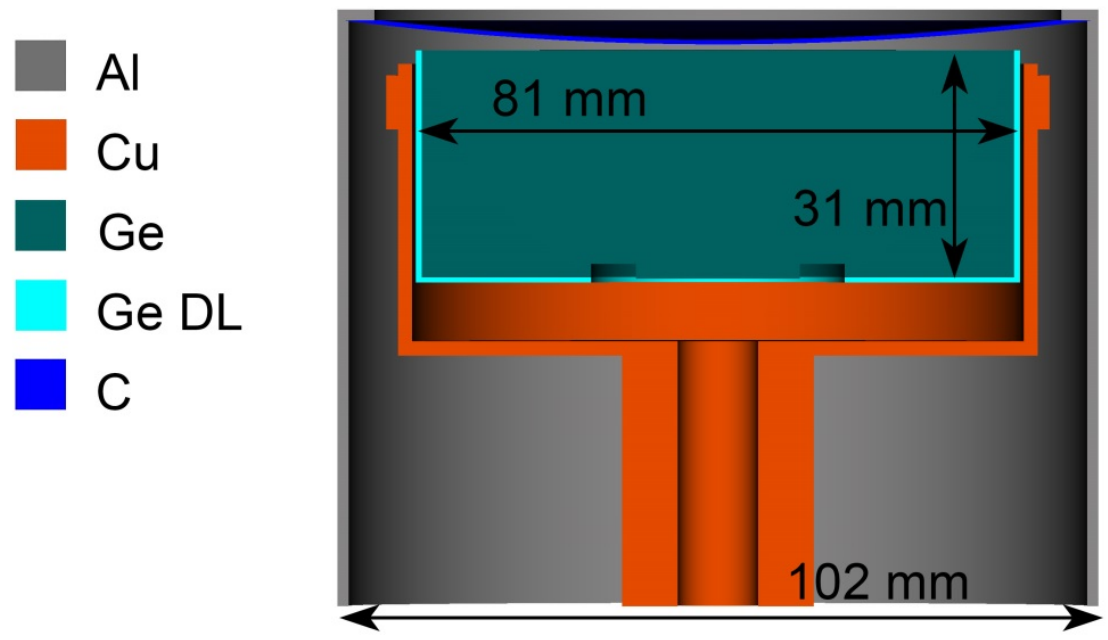

Fig. A3.1 Schematic representation of the EGSnrc model of detector DET08 used in the Monte Carlo simulations. Note that the model is not an exact representation of the reality.

Table A3.1 Full peak efficiencies for the source distributed inside the Ge volume. 15\% uncertainty will be used in flux calculations.

\begin{tabular}{|r|l|l|l|r|}
\hline Energy (keV) & Particle & histories & peak & \multicolumn{1}{|c|}{ FEP eff } \\
\hline 692 & e- & 6000000 & 5518951 & 0.92 \\
\hline 139.7 & P & 6000000 & 4745518 & 0.79 \\
\hline
\end{tabular}




\section{Appendix 4}

Veto solid angle coverage calculation. Geant4 model was developed with the source coming from upper hemisphere with $\cos ^{2} \varphi$ angular distribution; where $\varphi$ is zenith angle (Particle Data Group, 1994). Electrons of $10 \mathrm{eV}$ energy were modelled and flux was accumulated at the veto plate and in the detector. Solid angle convoluted by angular flux distribution was calculated using MC/ raytracing. All particles hitting the veto plate were stopped. The effect of covering the shield with 4 additional side plates (total reduction, $\mathrm{r}_{\mathrm{t}}$ ) was estimated from the measured reduction ( $\left.\mathrm{r}_{1}\right)$ with one plate on top and effective solid angle covered by single plate $(\Omega)$ :

$$
r_{t}=r_{1} \frac{2 \pi}{\Omega}
$$

Geant 4 calculation gave $\mathrm{r}_{1} / \mathrm{r}_{\mathrm{t}}$ ratio of 0.6 . BEGe detector 'transparency' effect for muons is neglected here. Detector is thin and wide so we expect that side veto plates would contribute even more because of the higher probability for interaction of muons hitting Ge crystal from side.

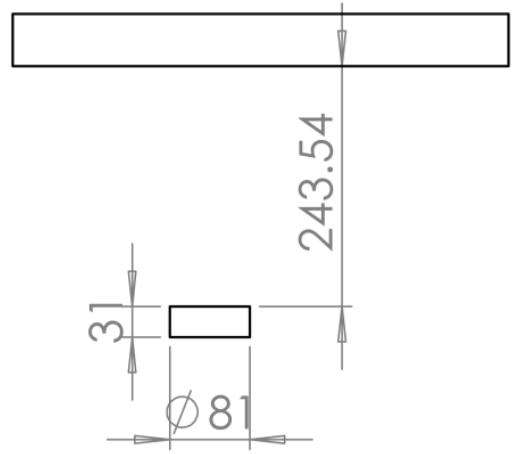

a)

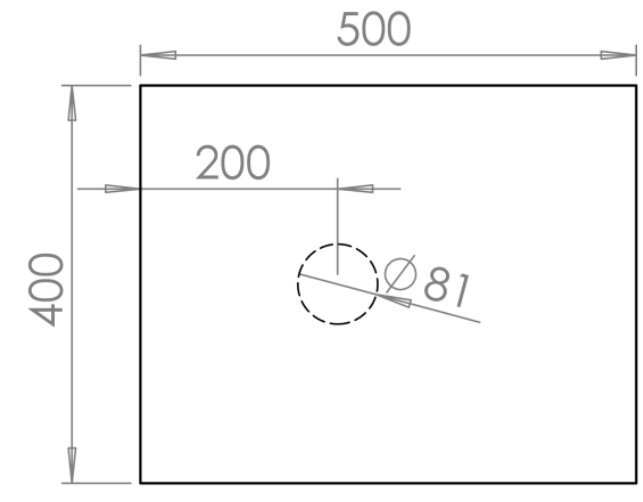

b)

Fig. A4.1 Geometry used in solid angle calculations, side view (a) and top view (b).

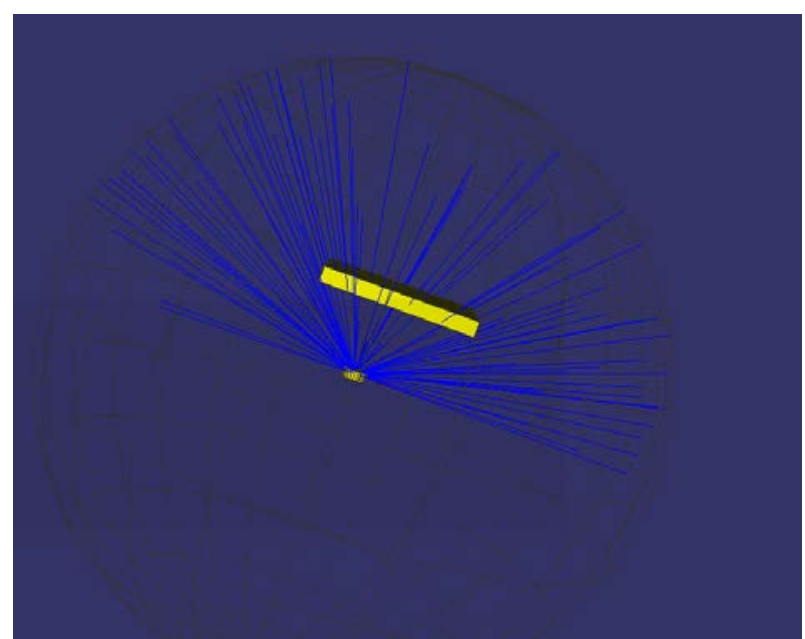

Fig. A4.2 The geometry used in Geant4 ray-tracing calculation. 


\section{Appendix 5}

Broad asymmetric inelastic neutron scattering peak area determination. Note the difference in number of channels when digital acquisition system is used ( $0.18 \mathrm{keV} / \mathrm{channel})$ and with analogue electronics (0.32 keV/channel).

Matlab code used for $692 \mathrm{keV}$ peak area determination:

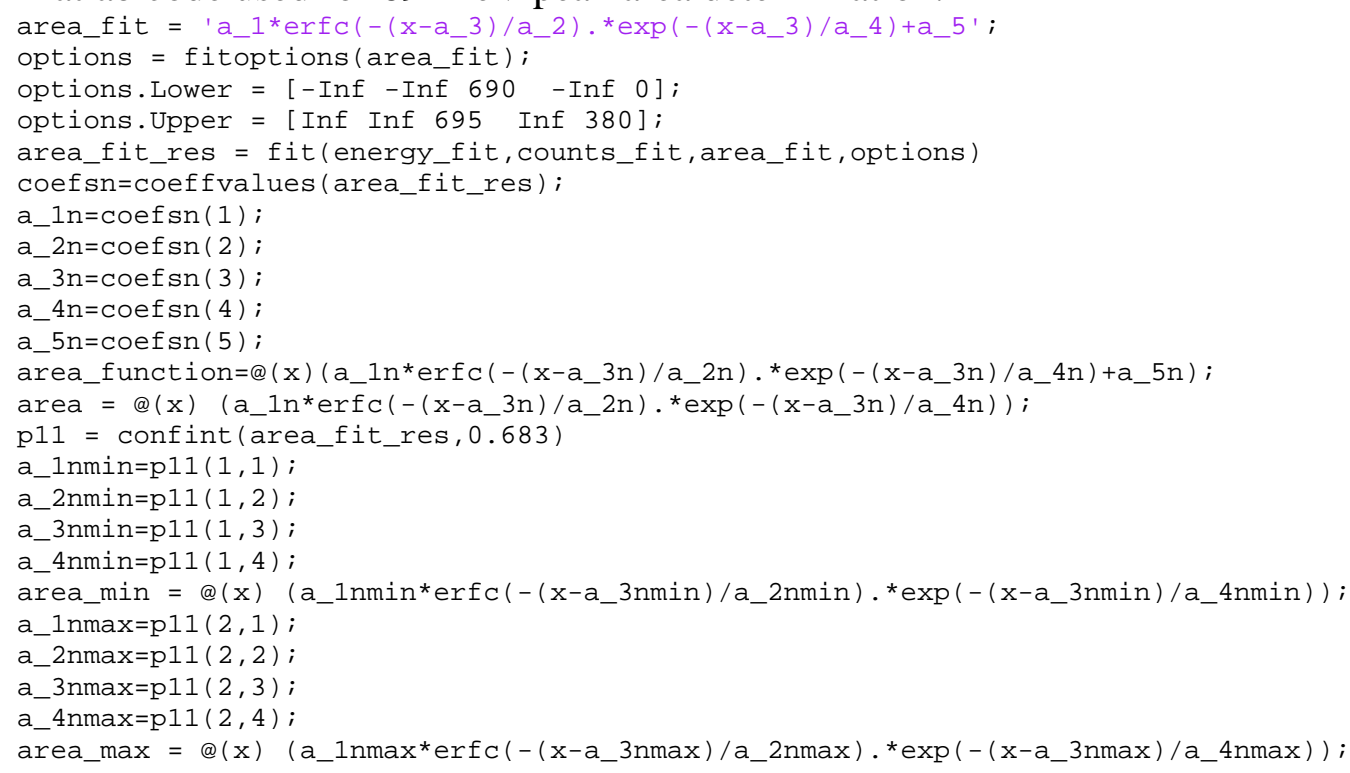

Matlab code used for $609 \mathrm{keV}$ peak area determination:

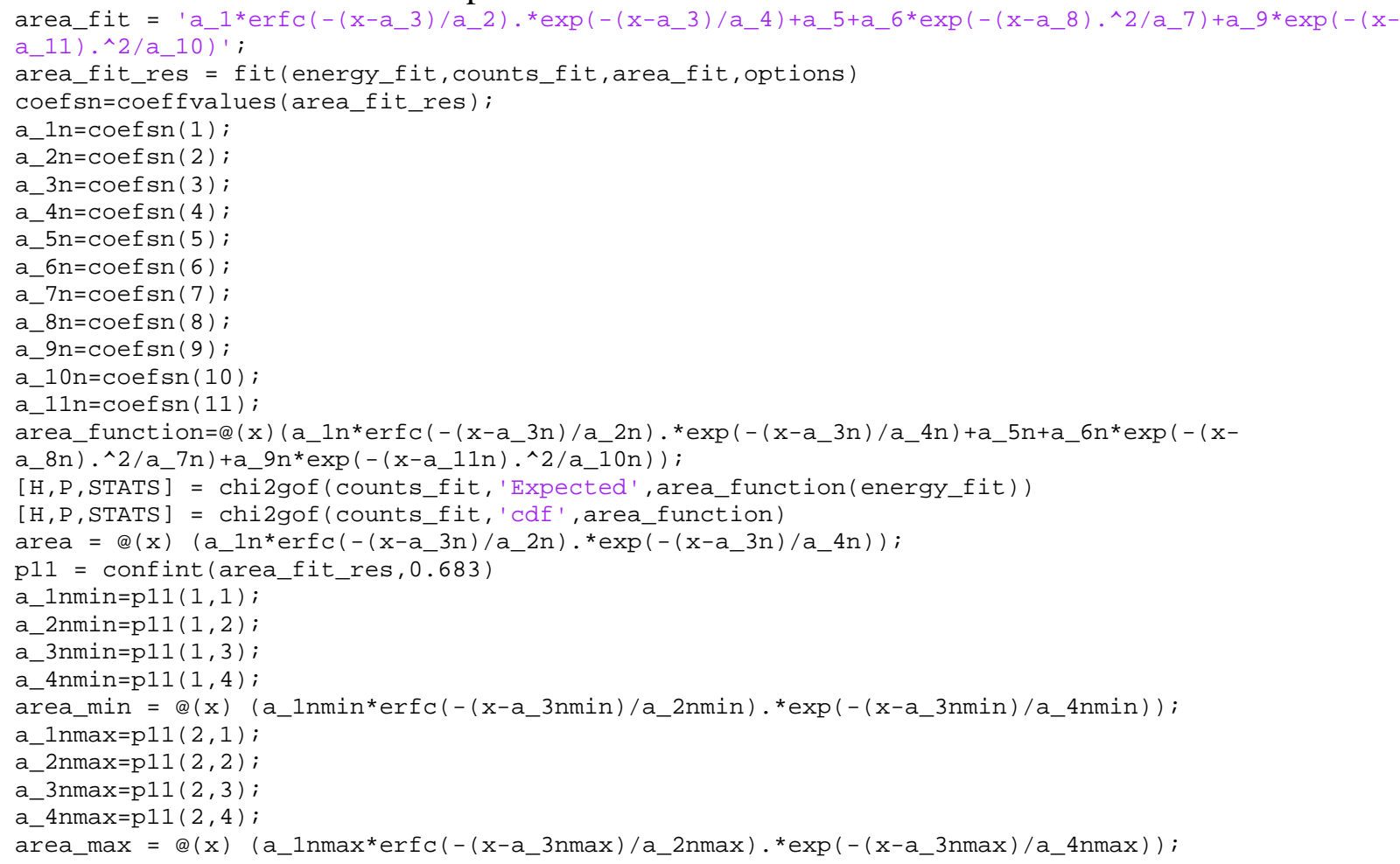




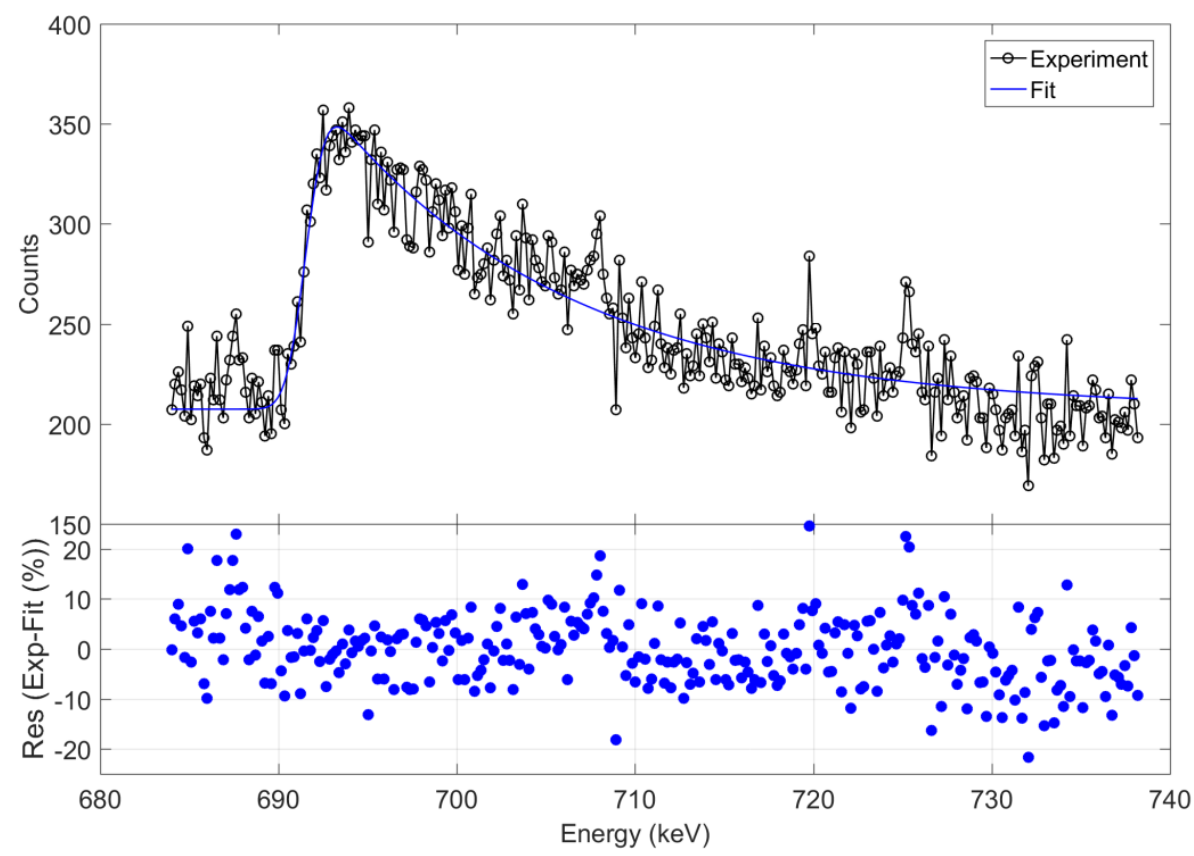

Fig. A5.1 Fast neutron activation line with plastic veto plate on the detector. The spectrum is 25 day background spectrum on DET008. The fit to ${ }^{72} \mathrm{Ge}\left(\mathrm{n}, \mathrm{n}^{\prime}\right){ }^{72} \mathrm{Ge}$ broad peak and background continuum is shown in blue.

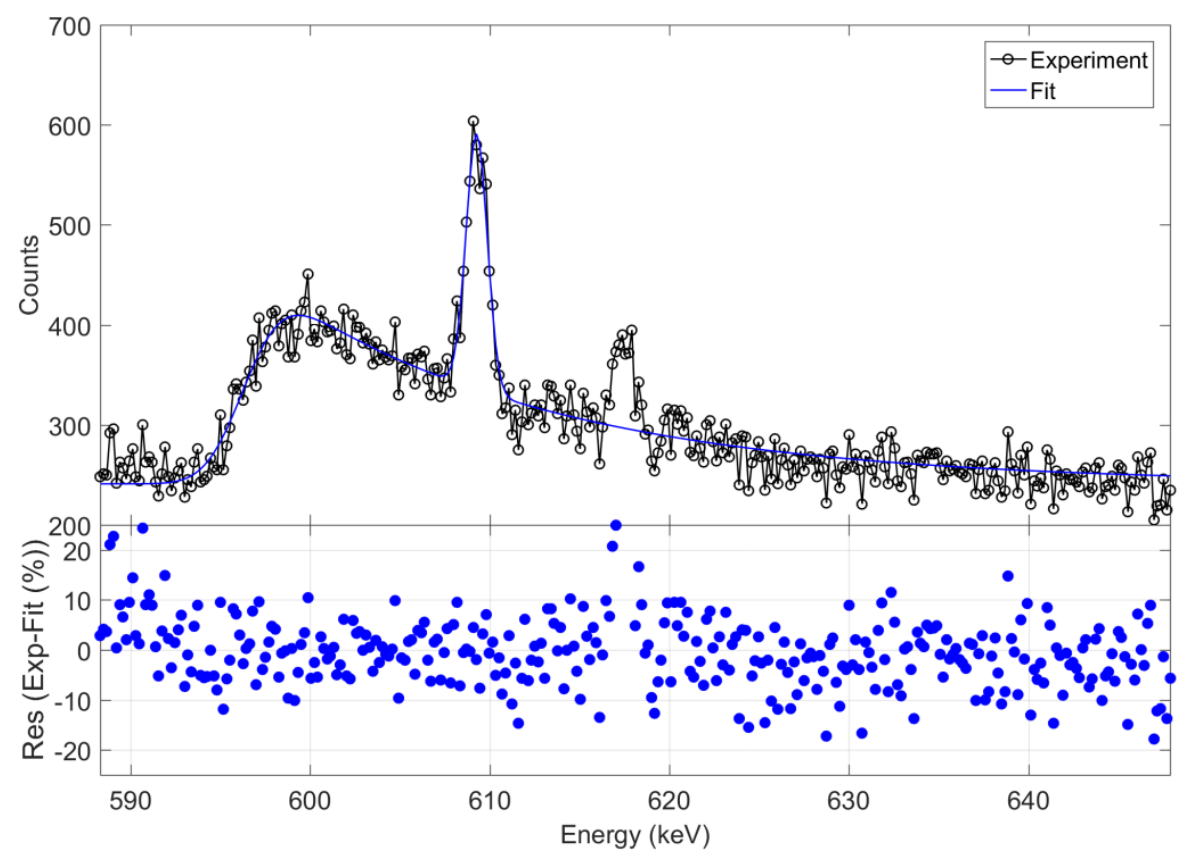

Fig. A5.2 The background spectrum measured for 25 days and with the plastic veto plate on. The fit to ${ }^{74} \mathrm{Ge}\left(\mathrm{n}, \mathrm{n}^{\prime}\right)^{74} \mathrm{Ge}$ broad peak, $609 \mathrm{keV}{ }^{214} \mathrm{Bi}$ background line and background continuum is shown in blue. Origin of the $617.6 \mathrm{keV}$ line is not resolved - 117Cd or Ge activation or both (it is broad)? 


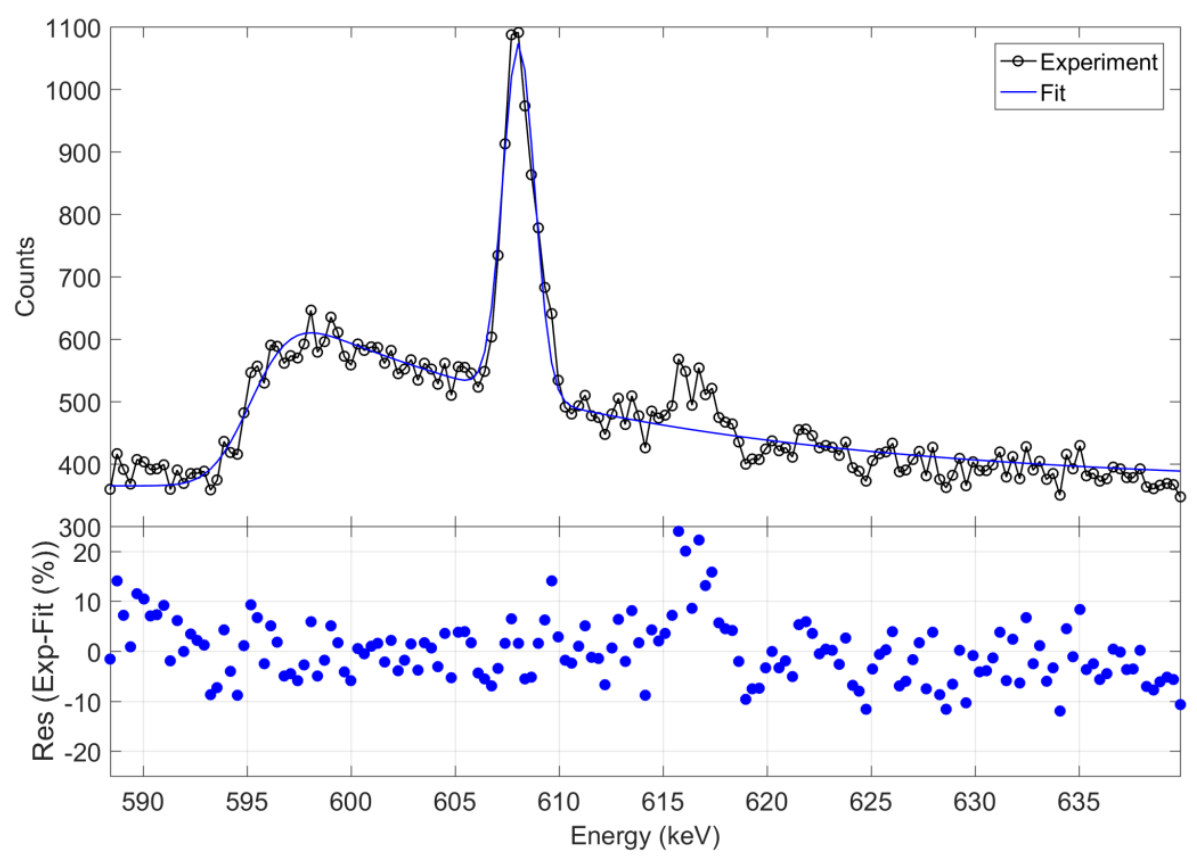

Fig. A5.3 The background spectrum measured for 21 days without the plastic veto plate on. The fit to ${ }^{74} \mathrm{Ge}\left(\mathrm{n}, \mathrm{n}^{\prime}\right)^{74} \mathrm{Ge}$ broad peak, $609 \mathrm{keV}{ }^{214} \mathrm{Bi}$ background line and background continuum is shown in blue. Origin of the $617.6 \mathrm{keV}$ line is not resolved - 117Cd or Ge activation or both (it is broad)?

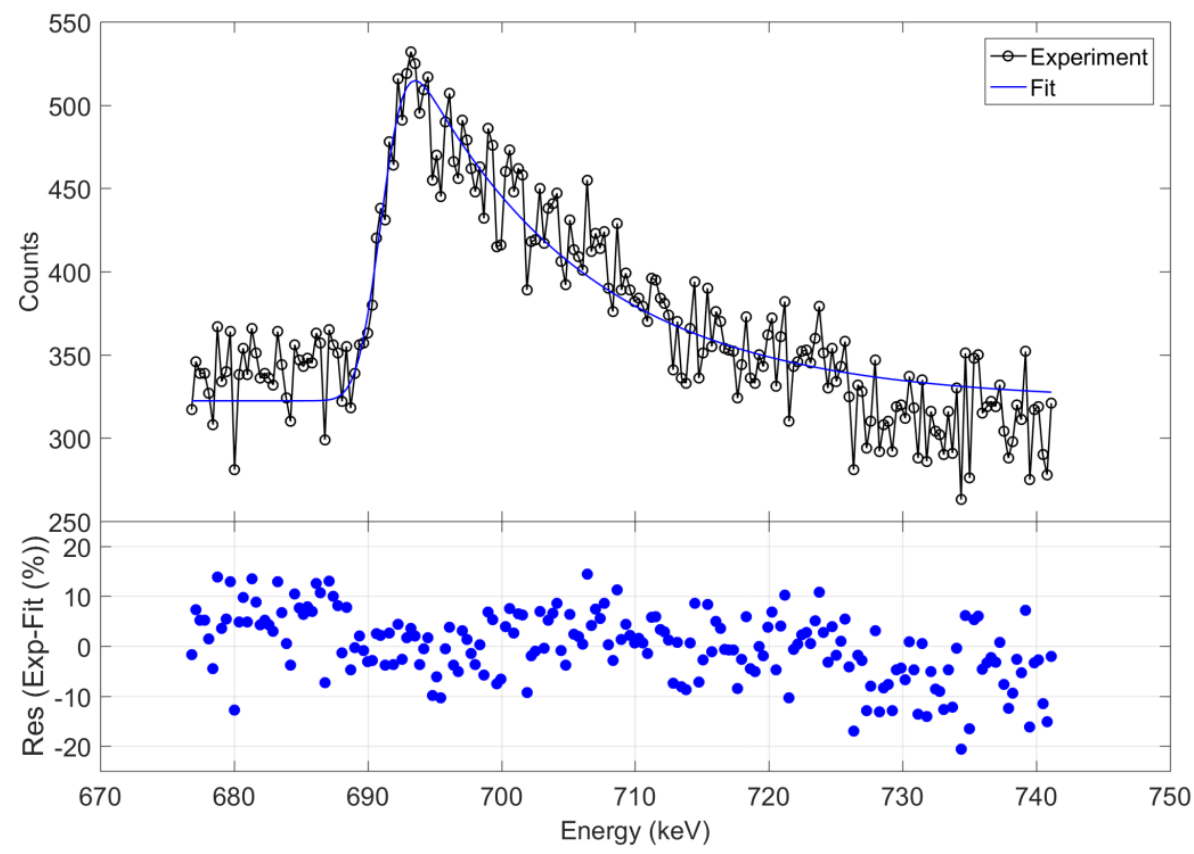

Fig. A5.4 Fast neutron activation line without the plastic plate on the detector. The spectrum is 21 day background spectrum on DET008. The fit to ${ }^{72} \mathrm{Ge}\left(\mathrm{n}, \mathrm{n}^{\prime}\right){ }^{72} \mathrm{Ge}$ broad peak and background continuum is shown in blue. 


\section{Bibliography}

Andreotti, E., Hult, M., Marissens, G., Lutter, G., Garfagnini, A., Hemmer, S., \& von Sturm, K. (2014). Determination of dead-layer variation in HPGe detectors. Applied Radiation and Isotopes, 87, 331-335.

Bruggeman, M., Vidmar, T., Amouriq, F., \& Verheyen, L. (2014). Efficiency calibration of BEGe and extended range detectors. Applied Radiation and Isotopes, 87, 356-360.

Mekarski, P., Zhang, W., Liu, C., \& Ungar, K. (2017). Accurate efficiency characterization of a BEGe detector in the low-energy range using empirical and Monte Carlo simulation approaches. Journal of Radioanalytical and Nuclear Chemistry, 314(1), 273-279. https://doi.org/10.1007/s10967-017-5352-5

Particle Data Group. (1994). Review of particle properties. Phys. Rev. D, 50(3), 1269. 